\title{
Dipeptidyl peptidase-4 inhibitors in the management of type 2 diabetes: safety, tolerability, and efficacy
}

\author{
Mary Elizabeth Cox' \\ Jennifer Rowell' \\ Leonor Corsino' \\ Jennifer B Green ${ }^{1,2}$
}

'Department of Medicine, Division of Endocrinology, Metabolism, and Nutrition. Duke University Medical Center, Durham, NC, USA; ${ }^{2}$ Department of Medicine, Division of Endocrinology, Durham Veterans Affairs Medical Center, Durham, NC, USA
Correspondence: Jennifer B Green Duke University Medical Center, Department of Medicine, Division of Endocrinology, Metabolism, and Nutrition, Duke Clinical Research Institute, DUMC Box 3850, Durham, NC 27705, USA

Tel + I 919-668-8500

$\mathrm{Fax}+1$ 919-668-7058

Email green094@mc.duke.edu
This article was published in the following Dove Press journal:

Drug, Healthcare and Patient Safety

28 January 2010

Number of times this article has been viewed

\begin{abstract}
Although glycemic control is an important and effective way to prevent and minimize the worsening of diabetes-related complications, type 2 diabetes is a progressive disease which often proves difficult to manage. Most affected patients will eventually require therapy with multiple medications in order to reach appropriate glycemic targets. The dipeptidyl peptidase-4 (DPP-4) inhibitors constitute a relatively new class of oral medications for the treatment of type 2 diabetes, which has become widely incorporated into clinical practice. This review summarizes the available data on the efficacy, safety, and tolerability of these medications.
\end{abstract}

Keywords: type 2 diabetes, pharmacotherapy, DPP-4 inhibitor, sitagliptin, vildagliptin, saxagliptin, alogliptin, linagliptin

\section{Introduction}

Although glycemic control is an important and effective way to prevent and minimize the worsening of diabetes-related complications, type 2 diabetes is a progressive disease which often proves difficult to manage. ${ }^{1-3}$ Most affected patients will eventually require therapy with multiple medications in order to reach appropriate glycemic targets. ${ }^{4}$ The number of new glucose-lowering therapies has increased dramatically over the past decade, and prospective agents continue to be developed as new physiologic targets are identified. There are a number of important considerations when choosing antihyperglycemic therapies for treatment of patients with type 2 diabetes. These include the glucose-lowering potency of the medication; the presence of comorbid conditions in the patient being treated; possible adverse side effects of the drugs being used; the risk of hypoglycemia with given classes or combinations of agents; and the potential for weight gain associated with various drug classes. Additional considerations include the impact of therapy on cardiovascular health and potential for beta cell preservation, as well as concern for carcinogenic or mitogenic properties of existing therapies.

The dipeptidyl peptidase-4 (DPP-4) inhibitor class of drugs represents one of the newest groups available for diabetes treatment. Two DPP-4 inhibitors are currently available in the United States: sitagliptin and saxagliptin. Vildagliptin is a third DPP-4 inhibitor available in Europe and many other countries, although approval in the US is still pending. Alogliptin and linagliptin are among the DPP-4 inhibitors still under development. These agents have an attractive mechanism of action, described in detail in the following sections, which complements those of many existing therapies. These agents have consistently been found to lower blood glucose and hemoglobin $\mathrm{A}_{1 \mathrm{c}}\left(\mathrm{HbA}_{1 \mathrm{c}}\right)$ 
levels, and the safety and tolerability of these medications have generally been good.

Although the potential for clinical use of DPP-4 inhibitors is extensive, the use of this drug class has not been formally recommended by all expert panels. In early 2009, the American Diabetes Association (ADA) and European Association for the Study of Diabetes (EASD) released a consensus statement for management of type 2 diabetes, including an updated algorithm for medication management. This algorithm focuses on lifestyle modifications and use of well-validated core therapies. Other than exenatide, which is listed as a "less-well-validated therapy," incretin-based therapies are not included. Reasons given for the exclusion of the DPP-4 inhibitor class from the algorithm are that these agents are no more effective in lowering glucose than is insulin; that the DPP-4 inhibitors have unestablished long-term safety; and that they are more expensive than insulin. ${ }^{4}$ However, data continue to accrue for these agents, and there may be selected cases in which use of these medications would be preferable to more traditionally prescribed therapies. This review will summarize the existing information on incretin physiology, as well as the efficacy, safety, and tolerability of the DPP-4 inhibitors.

\section{Physiology}

\section{Incretin hormones and the incretin effect}

Incretins are a group of insulinotropic hormones that are secreted by the gut in response to food intake. The class of hormones was first discovered in 1902, and in 1964 the incretin effect was described. ${ }^{5-7}$ The incretin effect refers to the more robust increase in insulin secretion in response to orally ingested glucose, as compared to the response elicited by glucose given intravenously. In the seminal trials, this effect was maintained despite the presence of higher blood glucose levels during the intravenous infusion. ${ }^{6,7}$ Subsequently, more details have emerged about the two hormones largely responsible for the incretin effect: glucagon-like peptide (GLP-1) and glucose-dependent insulinotropic polypeptide (GIP).

GLP-1 is the most potent known incretin. The level of GLP-1 rises quickly in response to food ingestion; this has direct effects on pancreatic endocrine function, including both insulin release from the beta cells and suppression of glucagon release from the alpha cells. There is some limited evidence that GLP-1 also acts at peripheral tissues to improve insulin utilization. ${ }^{8}$ Other effects of GLP-1 include slowed gastric emptying and the promotion of satiety at the level of the central nervous system. ${ }^{9}$ GIP, the other well-described but perhaps less well understood incretin hormone, promotes similar food and glucose-dependent insulin release. However, as opposed to GLP-1, it may exert a stimulatory effect on glucagon release. ${ }^{10}$ An important feature of both incretin hormones is that their activity is glucose-dependent: glucoselowering activity ceases when blood glucose levels fall below $65 \mathrm{mg} / \mathrm{dL} .{ }^{11}$ Furthermore, in animal models, both GLP-1 and GIP are suspected to have a stimulatory effect upon the growth, proliferation, and differentiation of beta cells. ${ }^{9}$ The half-lives of GLP-1 and GIP are only a few minutes long, as they are rapidly degraded to largely inactive metabolites by DPP-4. ${ }^{11}$

\section{Incretin hormones and DPP-4 in type 2 diabetes}

In individuals with type 2 diabetes, the incretin effect appears to be blunted. ${ }^{12}$ This blunting has been attributed to 2 factors: GLP-1 levels are lower and GIP exerts a lesser physiologic effect than seen in normoglycemic individuals. Responsiveness to GLP-1 is generally preserved; infusion of GLP-1 to individuals with diabetes has been shown to lower both postprandial and fasting blood glucose levels. ${ }^{11,13}$ Conversely, there appear to be relatively normal levels of GIP in persons with type 2 diabetes, but their physiologic response to GIP is diminished. ${ }^{14}$ Whether or not abnormalities in DPP-4 levels or degradative activity exist in patients with diabetes is still unclear.

The administration of DPP-4 inhibitors to individuals with type 2 diabetes has been shown to raise levels of endogenous GLP-1 and GIP, which in turn results in a glucose-appropriate increase in insulin secretion and suppression of glucagon release. ${ }^{15}$ In patients with type 2 diabetes, administration of DPP-4 inhibitors has been shown to improve markers of insulin processing, including homeostasis model assessment of beta cell function (HOMA- $\beta$ ) and the proinsulin:insulin ratio. ${ }^{16}$ Furthermore, there are animal data to suggest that pancreatic beta cell mass may be preserved; beta cells may even be stimulated to grow and proliferate in the presence of these agents. ${ }^{17}$ However, no comparable anatomic data in humans are available.

\section{Other roles of DPP-4 and homologous enzymes}

DPP-4 circulates in soluble form in the plasma and is responsible for the inactivation of a number of hormones and peptides. ${ }^{18}$ In addition to the incretin hormones, these include substance $\mathrm{P}$, whose fragment byproduct is important for sensory nerve transmission, and chemokines associated with interferon induction, macrophage signaling, eosinophil recruitment, and inhibition of mononuclear HIV-1 infection. ${ }^{19,20}$ DPP-4 inhibitors may also have a role in neuropeptide 
signaling by prolonging the action of neuropeptide $\mathrm{Y}$ and growth hormone-releasing hormone. ${ }^{21}$

In addition to the soluble form, there is a membrane-bound form of DPP-4, also called CD26, with an extracellular enzymatic domain and an intracellular domain involved with signal transduction cascades. Membrane-bound DPP-4 is found in epithelial cells, leukocytes, and other human tissues, including mammary glands, uterus, placenta, adrenal glands, exocrine pancreas, lymph nodes, gastrointestinal tract, and kidney. ${ }^{18,19} \mathrm{It}$ has multiple roles, with apparent involvement in T-lymphocyte activation..$^{20}$ DPP-4 levels have been found to be reduced in association with chronic rhinosinusitis and increased in association with multiple sclerosis and Graves' disease. ${ }^{21}$ Abnormal expression of both the soluble and membrane-bound forms has been associated with prostate cancer, melanoma, rheumatic diseases, HIV, and hepatitis $\mathrm{C}$ infection. ${ }^{19}$ In addition, T-cell hematologic malignancies, including lymphomas and lymphoproliferative disorders, have been associated with altered expression of DPP-4. ${ }^{19,20}$ Furthermore, rat transplantation studies indicate that DPP-4 inhibition may delay cardiac allograft rejection. ${ }^{19}$ It is as yet unclear to what extent this membrane-bound enzyme can be affected by pharmacological DPP-4 inhibition in vivo in humans. ${ }^{19,22,23}$

DPP-4 shares homology with other enzymes through a common enzymatic cleaving mechanism. ${ }^{18,22}$ These include DPP-7 (also called quiescent cell proline dipeptidase and DPP-2), DPP-8, DPP-9, fibroblast activation protein (FAP), attractin, and DPP-4 $\beta .^{22}$ Direct inhibition of DPP-7, DPP-8, and DPP-9 has been investigated in animal models. Administration of DPP-8 and DPP-9 inhibitors was associated with alopecia, thrombocytopenia, splenomegaly, reticulopenia, and gastrointestinal toxicity, while administration of DPP-7 inhibitors was associated with reduced reticulocyte count. ${ }^{18,22}$ Of the commercially available DPP-4 inhibitors sitagliptin, saxagliptin, and vildagliptin, interactions have been seen in vitro with only DPP-8 and DPP-9. ${ }^{24}$ However, no clear indication of DPP-8/DPP-9-related adverse events has been observed in clinical trials. ${ }^{24}$ It will be important for future development to focus on drugs that are specific inhibitors of DPP-4, and, if possible, of only the soluble form. Furthermore, investigations need to be conducted to examine effects of existing DPP-4 inhibitors in patients who are at risk for or who are affected by infectious and inflammatory conditions.

\section{Pharmacokinetics of available agents}

The mechanism of action of the various DPP-4 inhibitors appears to be similar. All of the named therapies inhibit
DPP-4 activity by greater than $80 \%$, which is the level of inhibition at which maximal glucose lowering is seen. ${ }^{25}$ Vildagliptin is metabolized at the kidney prior to excretion, saxagliptin is partially metabolized by the liver, and sitagliptin is largely unmetabolized prior to excretion by the kidney. ${ }^{26-29}$

Sitagliptin was the first commercially available DPP-4 inhibitor, and the agent with which there is to date the most clinical experience. Sitagliptin is dosed at $100 \mathrm{mg}$ daily; in healthy patients, this dose inhibits DPP- 4 activity by $80 \%$ over 24 hours. Sitagliptin is approved for use in patients with renal insufficiency, although a dose reduction is necessary in patients with moderate or severe renal dysfunction. Sitagliptin should be reduced to $50 \mathrm{mg}$ daily for creatinine clearance 30 to $<50 \mathrm{~mL} / \mathrm{min}$ and to $25 \mathrm{mg}$ daily for creatinine clearance $<30 \mathrm{~mL} / \mathrm{min}$. ${ }^{30,31}$ The medication may be taken once daily with or without food. Sitagliptin does not induce the CYP3A4 system and is not expected to interact with drugs metabolized through this pathway. Adverse drug-drug interactions have not been seen in studies evaluating combinations with glyburide, metformin, rosiglitazone, and pioglitazone. ${ }^{32-35}$ Outcomes data from trials of sitagliptin used in conjunction with insulin are not yet available. Drug metabolism does not differ between obese and lean subjects. ${ }^{27}$ Sitagliptin has been studied in patients with diverse ethnic backgrounds, including Japanese, Korean, Chinese, and Indian subjects, with apparent similar activity in all of these groups. ${ }^{36,37}$

Vildagliptin is prescribed at dosages of $50 \mathrm{mg}$ once or twice daily; absorption is not affected by food intake..$^{38}$ It has not been studied in patients with renal dysfunction, but renal clearance of the drug was noted to be reduced in elderly subjects. ${ }^{39}$ Similar to sitagliptin, it is excreted predominantly in the urine, although only $22 \%$ remains unmetabolized at the time of excretion. Metabolism occurs at the level of the kidney and not through the CYP3A4 system, thus vildagliptin does not affect this enzymatic system. ${ }^{28}$ Coadministration of metformin and vildagliptin in patients with type 2 diabetes resulted in small and clinically insignificant effects on the pharmacokinetics of each drug; however, neither drug should require a dose adjustment in the presence of the other. ${ }^{40}$ Significant drug interactions have not been seen in studies with glyburide, pioglitazone, ramipril, amlodipine, valsartan, simvastatin, digoxin, or warfarin. ${ }^{41-45}$ Drug metabolism does not appear to be affected by gender or body mass index (BMI) ${ }^{38}$ The pharmacokinetics of vildagliptin do not appear to differ significantly in the Chinese population compared to other ethnic groups studied. ${ }^{46}$ 
Saxagliptin is the most recently approved DPP-4 inhibitor. It is currently available as a once daily oral medication, usually dosed at $5 \mathrm{mg}$ daily. ${ }^{47}$ Saxagliptin is rapidly and extensively absorbed after oral dosing and can be taken with or without food. Saxagliptin has an active metabolite, M2, which is also cleared primarily by the kidneys. Saxagliptin is metabolized in part by the CYP3A4/5 enzymes, and its concomitant use with strong CYP3A4/5 inhibitors significantly increases the drug concentration. If such a drug combination is necessary, the saxagliptin dose should be decreased to $2.5 \mathrm{mg}$ daily. In patients with renal dysfunction evidenced by a creatinine clearance of $\leq 50 \mathrm{~mL} / \mathrm{min}$, dose reduction to $2.5 \mathrm{mg}$ daily is also recommended. ${ }^{29}$

Alogliptin and linagliptin are DPP-4 inhibitors in development but not yet commercially available. In brief, alogliptin is also a rapidly absorbed oral medication, with an activity half-life of 12 to 21 hours and predominantly renal excretion. At the doses likely to be recommended for clinical use, inhibition of DPP-4 is greater than $90 \% .{ }^{48}$ Linagliptin given at doses of 5 and $10 \mathrm{mg}$ daily to men with type 2 diabetes resulted in DPP-4 inhibition of greater than $90 \%$. It appears to have a long terminal half-life compared to the other agents - around 130 hours - leading to sustained inhibition of DPP-4 activity. Excretion of linagliptin is predominantly renal. ${ }^{49}$

None of the DPP-4 inhibitors have been studied in pregnant or lactating women, thus their use in these populations cannot be recommended.

\section{Efficacy \\ Glucose-lowering effects (Table I)}

DPP-4 inhibitors have been vigorously examined in randomized controlled trials and have generally been found to lower $\mathrm{HbA}_{1 \mathrm{c}}$ levels significantly more than placebo. Sitagliptin and vildagliptin are the most studied, and two major meta-analyses have been performed on available trial data. ${ }^{50,51}$ Amori et al determined that the overall weighted mean placebo-subtracted $\mathrm{HbA}_{1 \mathrm{c}}$ reduction for these two drugs is $0.74 \% .{ }^{50}$ In their 2009 meta-analysis, Monami et al examined both published and unpublished data of sitagliptin and vildagliptin efficacy. The average placebo-subtracted $\mathrm{HbA}_{1 \mathrm{c}}$ reductions were $0.70 \%$ and $0.68 \%$ respectively. ${ }^{51}$ Similar $\mathrm{HbA}_{1 \mathrm{c}}$ reductions with these two drugs have been seen in trials of both monotherapy and add-on therapy. Sitagliptin has been examined in combination with metformin, glimepiride, metformin plus glimepiride, and pioglitazone. ${ }^{32,52-55}$ Noninferiority comparisons of glucose lowering have found that sitagliptin therapy is noninferior to glipizide or rosiglitazone but somewhat less effective than full-dose metformin or exenatide.$^{54,56-58}$ Vildagliptin has been examined in combination with metformin, glimepiride, pioglitazone, and insulin. ${ }^{59-63}$ Noninferiority comparisons have concluded that vildagliptin is similar in efficacy to rosiglitazone, pioglitazone, or acarbose, but is not as effective as metformin. ${ }^{64-69}$

Two studies of sitagliptin monotherapy and 1 study of vildagliptin monotherapy reported substantially larger reductions in $\mathrm{HbA}_{1 \mathrm{c}}$ for patients with high baseline $\mathrm{HbA}_{1 \mathrm{c}}$ values. Raz et al reported a trial of sitagliptin $100 \mathrm{mg}$ daily, which resulted in a mean placebo-subtracted $\mathrm{HbA}_{1 \mathrm{c}}$ reduction of $1.2 \%$ for the group with baseline $\mathrm{HbA}_{1 \mathrm{c}}>9 \%$ as compared to reductions of $0.44 \%$ for baseline $\mathrm{HbA}_{1 \mathrm{c}}<8 \%$ and $0.6 \%$ for baseline $8 \%$ to $9 \% .{ }^{16}$ Aschner et al reported similar mean placebo-subtracted reductions: $0.57 \%, 0.81 \%$, and $1.52 \%$ for baseline $\mathrm{HbA}_{1 \mathrm{c}}$ of $<8 \%, 8 \%$ to $9 \%$, and $>9 \%$, respectively. ${ }^{70}$ Pratley et al reported a trial of vildagliptin $25 \mathrm{mg}$ twice daily resulting in a mean placebo-subtracted $\mathrm{HbA}_{1 \mathrm{c}}$ reduction of $0.6 \%$ in patients with baseline $\mathrm{HbA}_{1 \mathrm{c}}<8 \%$ and a reduction of $1.2 \%$ in those with baseline of $8 \%$ to $9.5 \% .{ }^{71}$ Interestingly, upon meta-analysis, there was a nonsignificant trend toward a greater reduction of $\mathrm{HbA}_{1 \mathrm{c}}$ in trials enrolling patients with a mean baseline $\mathrm{HbA}_{1 \mathrm{c}}$ less than $8 \% .{ }^{51} \mathrm{~A}$ clear explanation for this discrepancy is not currently available.

Five efficacy trials for saxagliptin have been published, with mean placebo-subtracted $\mathrm{HbA}_{1 \mathrm{c}}$ reductions ranging from $0.45 \%$ to $0.83 \%{ }^{47,72-74}$ However, Jadzinsky et al recently reported a large, 24-week randomized, controlled trial of saxagliptin $10 \mathrm{mg}$ versus a combination of saxagliptin and metformin; a 1.7\% mean placebo-subtracted $\mathrm{HbA}_{1 \mathrm{c}}$ reduction was seen in the saxagliptin monotherapy group. This trial had a higher mean baseline $\mathrm{HbA}_{1 \mathrm{c}}$ level, 9.5\%, compared to other saxagliptin monotherapy trials, where mean baseline $\mathrm{HbA}_{1 \mathrm{c}}$ levels otherwise ranged from $7.8 \%$ to $8.4 \% \cdot{ }^{47,72-75}$ Rosenstock et al reported a similarly large reduction from baseline of $1.87 \%$ in a small open-label cohort with a mean baseline $\mathrm{HbA}_{1 \mathrm{c}}$ of $10.7 \% .{ }^{47}$ Efficacy of saxagliptin was maintained in two 24-week combination trials, one each with metformin and glyburide. ${ }^{74,75}$

Three efficacy trials have been reported for alogliptin, which have shown mean placebo-subtracted $\mathrm{HbA}_{1 \mathrm{c}}$ reductions ranging from $0.39 \%$ to $0.58 \%$. Monotherapy data are not available, but combinations of alogliptin with metformin, glyburide, and insulin appear to yield similar glucoselowering effects. ${ }^{76-78}$

Efficacy data for linagliptin are pending; currently 2 trials are recruiting participants. The first will examine 


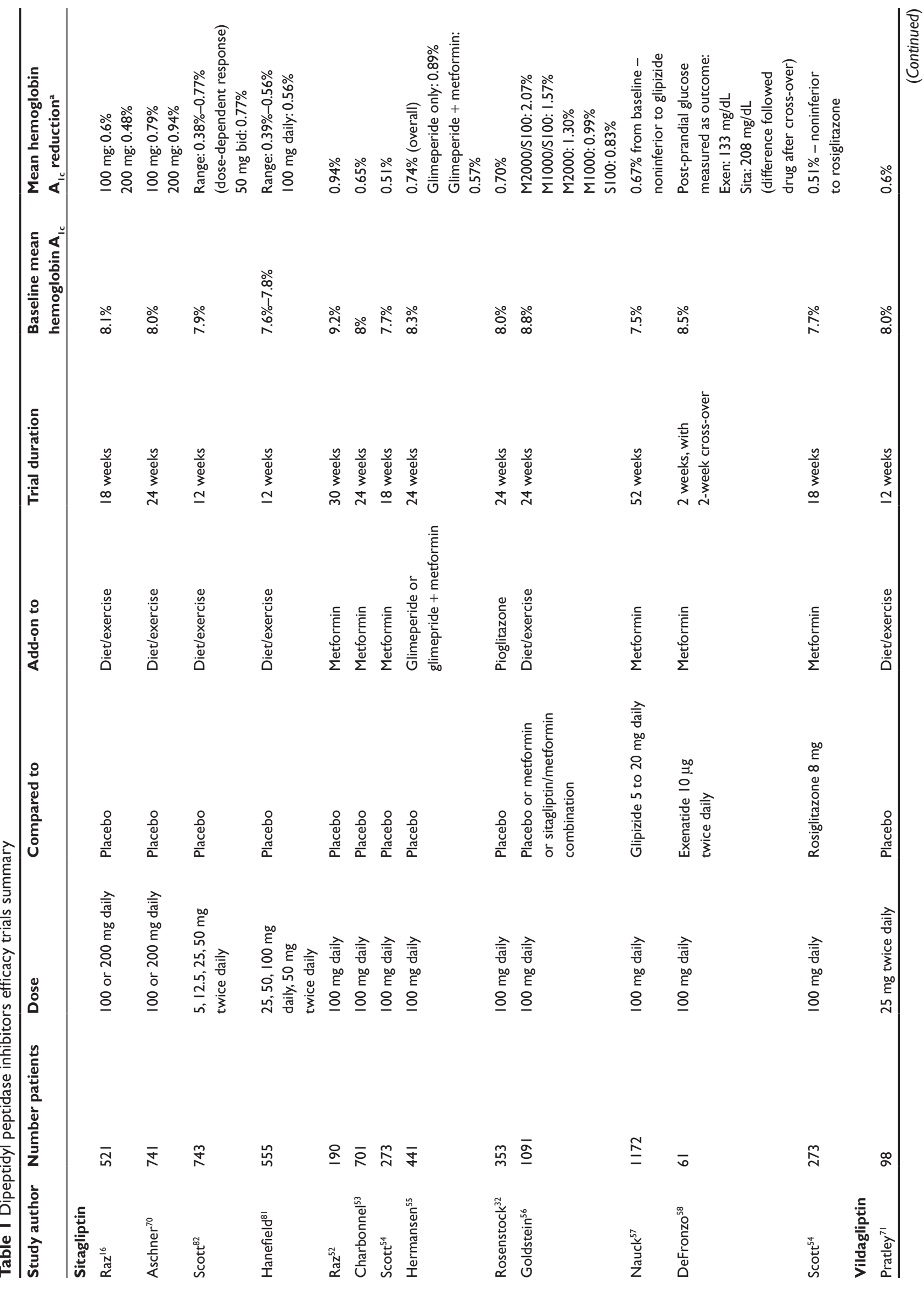




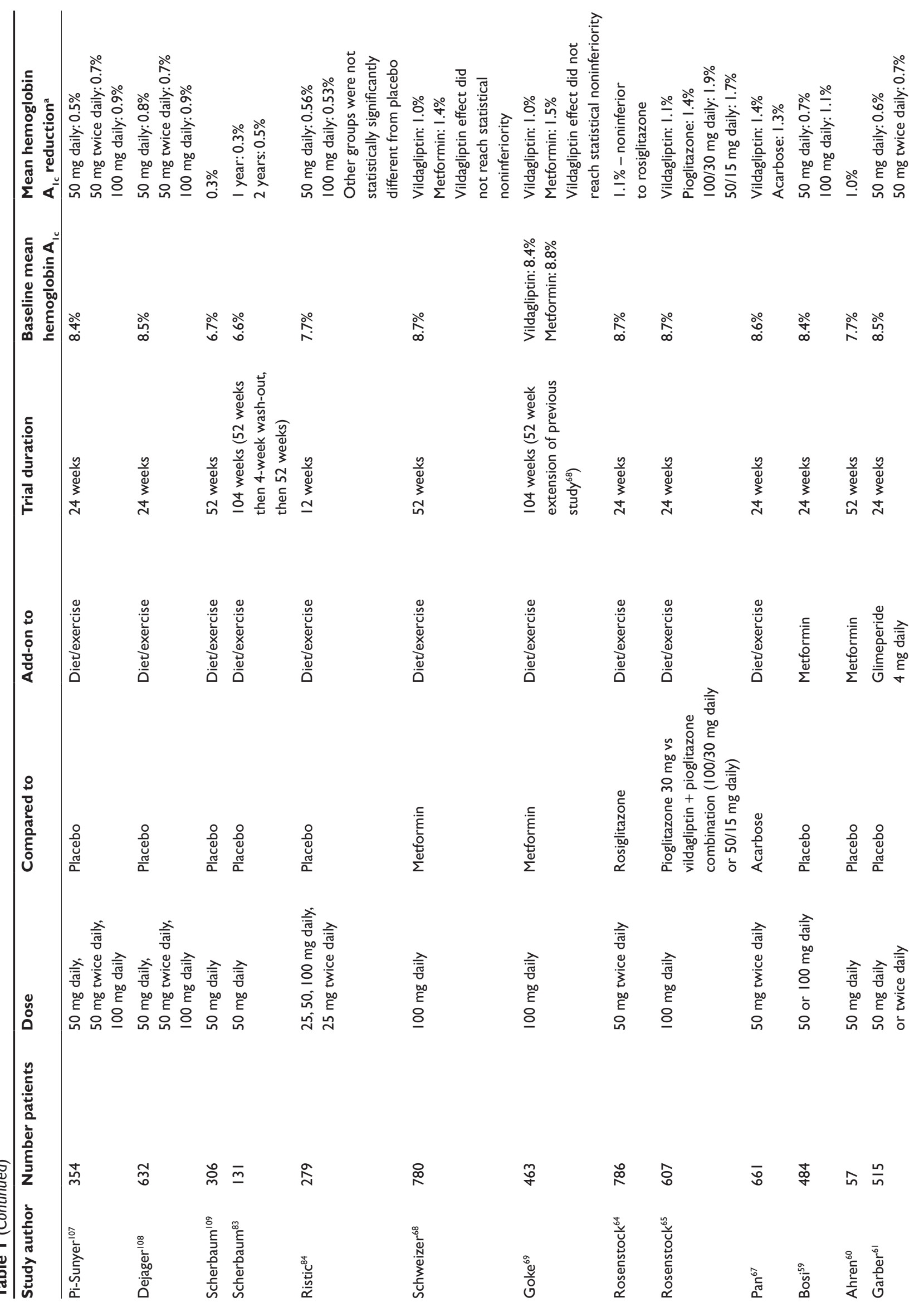




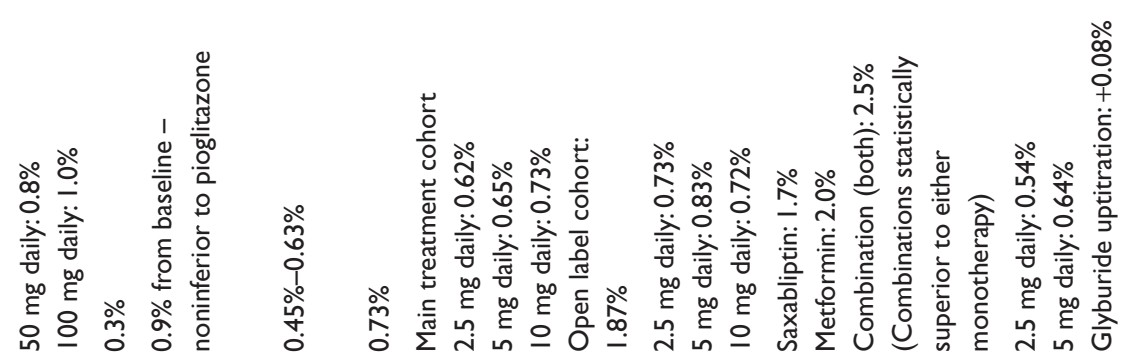

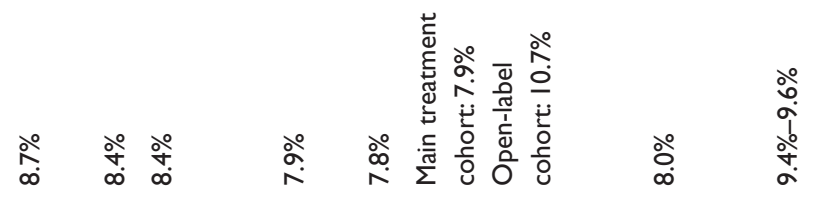

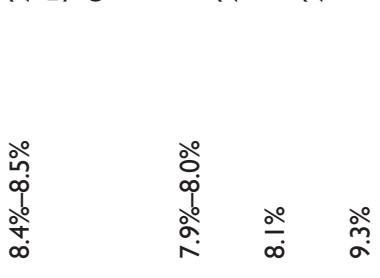

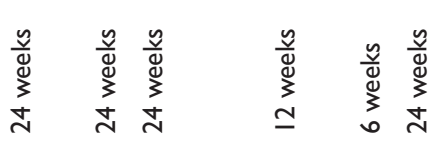
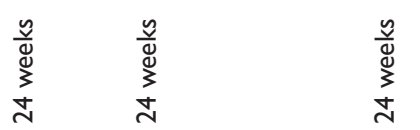

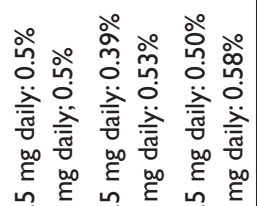

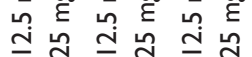

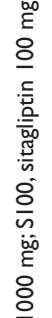

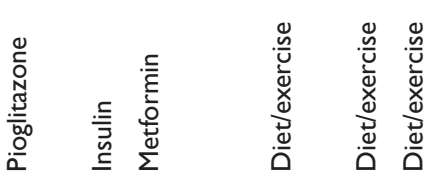

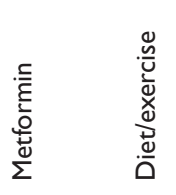

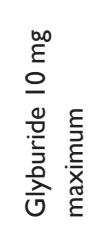

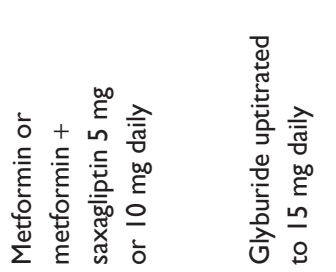

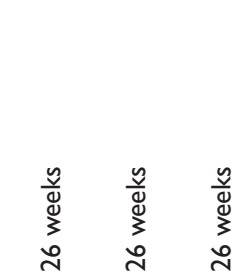

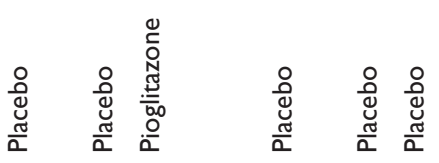

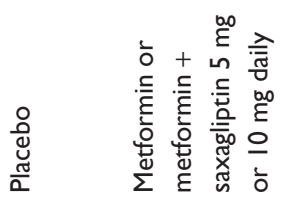

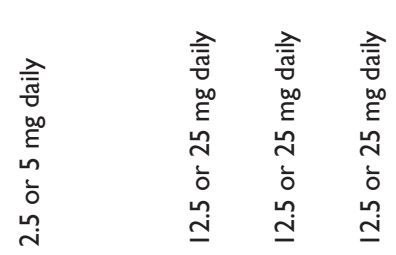

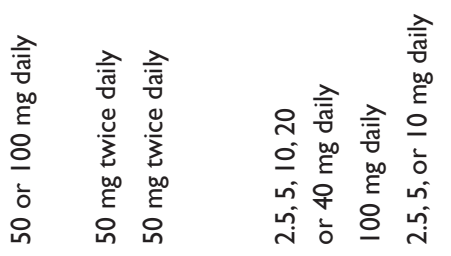

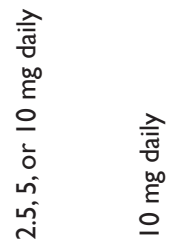

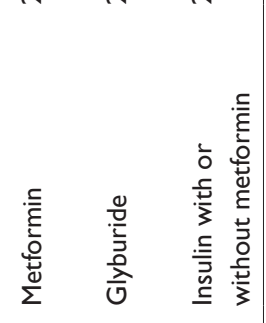


glucose-lowering effects of linagliptin $2.5 \mathrm{mg}$ twice daily as add on to metformin, ${ }^{79}$ and the second will examine its efficacy as add-on therapy to insulin..$^{80}$

\section{Effects of therapies on beta cell function, alpha cell function, and peripheral glucose metabolism}

One attractive feature of DPP-4 inhibitors is the potential beneficial effect they exert on pancreatic beta cells. In efficacy trials of sitagliptin, vildagliptin, and saxagliptin, investigators have consistently reported improvements in markers of beta cell function, including HOMA- $\beta$, insulin:proinsulin ratio, glucose to insulin concentration-time curve (AUC) ratio, and the insulinogenic index. ${ }^{32,52,53,55,59,61,62,70-72,81-85}$ Islet function has also been shown to improve with administration of vildagliptin in patients with impaired glucose tolerance that have not yet progressed to type 2 diabetes. ${ }^{86}$ However, it has not yet been shown that this therapy delays progression of the disease in these patients. Fasting insulin levels also increase with DPP-4 inhibition, further supporting an improvement in beta cell function. A small study conducted by D'Alessio et al examined fasting insulin production in patients with well-controlled type 2 diabetes on metformin or dietary therapy, given add-on treatment with vildagliptin. The study described DPP-4 induced improvement in fasting islet cell function even in patients with well-controlled diabetes. ${ }^{87} \mathrm{In}$ rodent models, studies of DPP-4 inhibitors have demonstrated that exposure to these agents inhibits apoptosis, augments beta cell replication and increases beta cell mass. ${ }^{88}$ However, rodents have high rates of beta cell turnover, which may allow for a very robust physiologic response to DPP-4 inhibition; it is unclear whether the findings of beta cell proliferation and growth can be translated to humans.

Unlike the other DPP-4 inhibitors, alogliptin studies have not as clearly supported an improvement in beta cell function other than that demonstrated by glucose lowering. Although $\mathrm{db} / \mathrm{db}$ mice treated with alogliptin showed improvement in markers of beta cell function, studies in humans have not documented improvement in HOMA- $\beta$ or proinsulin:insulin ratio. ${ }^{89,76,77}$

In addition to their effects on the beta cells, DPP-4 inhibitors appear to have effects on the alpha cells as well. Alpha cells are dysfunctional in patients with type 2 diabetes, resulting in unregulated glucagon production. ${ }^{90}$ As a result, hepatic glucose production is not suppressed during times of hyperglycemia. Incretin hormones enhance the sensitivity of alpha cells to glucose. Increases in incretin hormone levels via DPP-4 inhibition with both vildagliptin and sitagliptin have been shown to have this physiologic effect, demonstrated by appropriately decreased post-prandial glucagon levels. ${ }^{8,91}$

There is evidence to suggest that vildagliptin may also improve peripheral glucose utilization, as assessed by Azuma et al with an insulin infusion study. The authors speculate that there may be a direct effect of GLP-1 or GIP on glucose uptake. ${ }^{8}$ Conversely, Hanefield et al examined measures of insulin resistance, specifically the quantitative insulin sensitivity check index (QUICKI) and HOMA-insulin resistance, in a study of sitagliptin; there was no difference from placebo in these measures. ${ }^{81}$ Further data are needed to establish whether there is, in fact, an incretin effect at peripheral tissues or whether this may be a unique effect of vildagliptin.

\section{Nonglycemic effects, including cardiovascular effects}

In addition to the effects on glucose metabolism, incretin hormones may also affect lipids, blood pressure, and cardiovascular health. Endogenous GLP-1 has been shown to slow gastric emptying, increase satiety, and reduce food intake. ${ }^{9}$ Despite the increase in endogenous GLP-1 levels with administration of DPP-4 inhibitors, these medications have not been shown to exert similar effects. ${ }^{92}$ When compared directly with exenatide, a GLP-1 agonist, patients taking exenatide had reduced caloric intake and slowed gastric emptying in response to that drug, while patients taking sitagliptin did not. ${ }^{58}$ GLP-1 agonist therapy has also been associated with mild systolic blood pressure reduction of 2 to $6 \mathrm{mmHg}$; this effect has not yet been demonstrated with DPP-4 inhibitors. ${ }^{93}$ Finally, therapy with GLP-1 agonists is associated with weight loss, while the DPP-4 inhibitors are generally weight neutral. ${ }^{94,58}$

Vildagliptin and sitagliptin have been examined for lipidlowering effects, particularly for changes in post-prandial triglyceride levels. In an efficacy study comparing vildagliptin with rosiglitazone, patients treated with vildagliptin $50 \mathrm{mg}$ twice daily experienced reductions in triglycerides (9\%), total cholesterol (14\%), low-density lipoprotein (LDL) cholesterol (16\%), and non-high-density lipoprotein (HDL) cholesterol (16\%); all were statistically greater reductions than those seen with rosiglitazone. Vildagliptin therapy also increased HDL cholesterol, although it was not to the same extent as rosiglitazone, $4 \%$ versus $9 \%$ respectively ${ }^{64}$ Vildagliptin therapy has been examined specifically for reduction of postprandial triglyceride-rich lipoproteins in patients 
with type 2 diabetes; reductions in both apolipoprotein B48 and cholesterol components were reported. ${ }^{95}$ Modest improvements in HDL cholesterol, about 4\%, and reductions in triglyceride levels of $9 \%$ have also been reported with sitagliptin therapy. Total, LDL, and non-HDL cholesterol were not improved. ${ }^{82}$ Reductions in lipid levels appear to be independent from the glucose-lowering effects of these drugs, as sulfonylureas and thiazolidinediones with similar glucose-lowering efficacy, have not shown the same lipid effects in head-to-head comparisons. ${ }^{64,82}$

\section{Safety and tolerability Side effects}

There have been numerous individual trials and 3 large meta-analyses to examine the safety and tolerability of the DPP-4 inhibitors as a class. ${ }^{21,50,51}$ The analyses have shown that these medications are generally well-tolerated in the short term. With respect to hypoglycemia, the DPP-4 inhibitors have performed well. Their use has not been commonly associated with any degree of hypoglycemia. Although a few individual trials have found an increase in mild hypoglycemia when DPP-4 inhibitors are combined with other antidiabetic medications, ${ }^{38,55,60,65} 2$ meta-analyses have shown that there has been no significant difference from placebo, even when DPP-4 inhibitors are combined with sulfonylureas or insulin. ${ }^{21,51}$ Monami et al examined unpublished data and described five cases of severe hypoglycemia in sitagliptin monotherapy; these cases were fewer than those in sulfonylurea comparator groups and were not discussed in the published literature. ${ }^{51}$ Another feature in favor of the use of DPP-4 medications is that they have not been associated with weight gain. Metaanalyses of sitagliptin, vildagliptin, alogliptin, and saxagliptin concluded that there has been no clinically significant effect on BMI in placebo-controlled trials. ${ }^{51}$

Reported side effects have generally been mild, such as increased rate of headaches with vildagliptin and increased rates of upper respiratory tract infections with sitagliptin. ${ }^{51}$ Increased rates of other mild infections, such as urinary tract infection, have been reported in individual trials and were associated with use of sitagliptin in a 2009 Cochrane review. ${ }^{21}$ However, a more recent meta-analysis did not confirm this association. ${ }^{51}$ In the postmarketing period, the use of sitagliptin has been associated with cases of mild to severe hypersensitivity reactions, including anaphylaxis, angioedema, and exfoliative skin conditions. These have occurred in the first few months of therapy; in one case, after the first dose. Continued use of or re-exposure to sitagliptin is contraindicated in patients who have experienced hypersensitivity reactions. ${ }^{96}$ Vildagliptin has been associated with rare cases of hepatic dysfunction, and should not be used in patients with pre-existing moderate to severe hepatic failure. ${ }^{97}$ Vildagliptin was also associated with a skin blistering condition in nonclinical toxicology studies with primates. This has not been reported in human studies at recommended therapeutic dosages, and is not reported in post-marketing data. ${ }^{98}$ More studies are needed to examine the potential immunomodulatory effects of vildagliptin and determine whether they are greater than that seen with use of other agents in this class.

The US Food and Drug Administration (FDA) recently called attention to a number of cases of acute pancreatitis, which were temporally associated with the initiation of sitagliptin. ${ }^{99}$ This announcement raises concern given that a similar association had been observed with the GLP-1 agonist exenatide. ${ }^{100}$ The classes of drugs that utilize the incretin pathway are known to have direct effects on the structure of the pancreas in rodent models, suggesting the possibility for a causal relationship with pancreatitis, although the mechanism is unclear. In one rodent study, use of GLP-1 receptor agonists was associated with increase in pancreatitis-associated gene expression but not with pancreatitis. ${ }^{101}$ Matveyenko et al conducted a rodent model study to examine the effects on the pancreas of metformin and sitagliptin in combination. The two drugs appeared to have synergistic effect to preserve beta-cell mass and function, but use of sitagliptin was associated with increased pancreatic ductal turnover, ductal metaplasia, and, in one rat, pancreatitis. ${ }^{102}$ These findings do raise concern; however, this information has yet to be confirmed in humans. Human data exist in the form of a retrospective analysis of around 88,000 patient hospitalization records, which examined rates of admission for acute pancreatitis in patients using incretin-based therapies (exenatide and sitagliptin) compared to matched groups of patients using metformin and glyburide. They found that hospitalizations for acute pancreatitis within 1 year of initiation of the respective drugs were similar for the four medications, with a rate of $0.13 \%$ per year of patients on exenatide and $0.12 \%$ per year for patients on sitagliptin. ${ }^{103}$ Given that the human data at this point are limited to postmarketing reports and retrospective data analysis, the true relationship of pancreatitis to incretin-based therapy remains unknown. Given the baseline rate of pancreatitis in people with diabetes, it is currently difficult to know if reports of pancreatitis in people on incretin therapies are truly attributable to drug usage. Data accumulated from large, long-term trials with sitagliptin and other DPP-4 inhibitors may provide much needed information 
regarding this relationship. For now, the FDA recommends that physicians warn patients about the potential risk as well as the symptoms of pancreatitis, and discontinue the drugs if symptoms or signs of pancreatitis develop. ${ }^{99}$

The FDA now requires that therapies approved to treat type 2 diabetes should provide data to demonstrate that the therapy will not result in an unacceptable increase in cardiovascular risk. ${ }^{104}$ Saxagliptin was the first drug approved following establishment of this guideline; its use was not associated with an increased risk of cardiovascular events in pooled data from eight pre-marketing clinical trials. ${ }^{105}$ However, the number of cardiovascular events occurring during these trials was inadequate to confidently exclude a differential effect; thus a long-term cardiovascular outcomes trial of this medication will be required. Although analysis of data from early studies of sitagliptin and vildagliptin found that mortality and cardiovascular event rates were similar between these drugs and comparators, no individual trial with these agents was powered to examine this outcome. ${ }^{51} \mathrm{~A}$ long-term cardiovascular outcomes trial of sitagliptin therapy in individuals at high risk for such complications began enrollment in December of 2008. The Trial Evaluating Cardiovascular Outcomes with Sitagliptin (TECOS) is an international trial of 14,000 individuals with diabetes and cardiovascular disease which will assess the impact of sitagliptin therapy on events including cardiovascular death, myocardial infarction, stroke, and hospitalization for unstable angina. ${ }^{106}$

\section{Conclusion}

Therapy for type 2 diabetes is complex; many patients require multiple medications to reach optimal glycemic targets. As outlined in the ADA/EASD algorithm for diabetes medications, there are multiple potential combinations of medications for any individual; the provider must consider co-morbidities and patient preferences when making these decisions. Although the DPP-4 inhibitor class is not yet wellstudied enough to have been included in the algorithm, studies suggest that these drugs' mechanisms of action complement those of traditionally used diabetes medications. The DPP-4 inhibitors have been criticized for having lower glucoselowering efficacy than other available therapies, particularly insulin. ${ }^{4}$ However, the active comparator trials data suggest that they can be as effective as more traditionally prescribed therapies. Furthermore, they are generally well tolerated, do not cause weight gain, and may provide some beta cell protection. Unlike many traditional medications, these drugs rarely cause hypoglycemia and some agents have no major contraindications to use. These attributes make this class of drugs attractive for use in the elderly, for those who have multiple co-morbidities precluding the use of other medications, and for those in whom insulin therapy proves difficult.

Data on these drugs continue to be accrued, and it is likely that the safety concerns related to the immune system and pancreatitis will be prospectively and more comprehensively addressed. Long-term trials are also needed to determine if preliminary data suggesting beta cell preservation will be borne out in clinical practice. Further investigations are also needed to examine long-term effects of these agents on cardiovascular outcomes and mortality.

\section{Acknowledgments}

Drs Cox and Rowell are supported by NIH Training Grant T32-DK007012-31 at Duke University Medical Center.

\section{Disclosures}

Dr Green is a member of the Takeda and Merck speakers' bureaus. She also performs research for which Merck is the sponsor.

\section{References}

1. UK Prospective Diabetes Study (UKPDS) Group. Intensive blood glucose control with sulphonylureas or insulin compared with conventional treatment and risk of complication in patients with type 2 diabetes (UKPDS 33). Lancet. 1998;352:837-853.

2. UK Prospective Diabetes Study (UKPDS) Group. Effect of intensive blood glucose control with metformin on complication in overweight patients with type 2 diabetes (UKPDS 34). Lancet. 1998;352:854-865.

3. Ohkubo Y, Kishiwawa H, Araki E, et al. Intensive insulin therapy prevents the progression of diabetic microvascular complications in Japanese patients with NIDDM: a randomized prospective 6-year study. Diabetes Res Clin Pract. 1995;28:103-117.

4. Nathan NM, Buse JB, Davidson MB, et al. Medical management of hyperglycemia in type 2 diabetes: a consensus algorithm for the initiation and adjustment of therapy. Diabetes Care. 2009;32:193-203.

5. Bayliss WM SE. The mechanism of pancreatic secretion. J Physiol. 1902;28(5):325-353.

6. Elrick H SL, Hlad CJ Jr, Arai Y. Plasma insulin response to oral and intravenous glucose administration. J Clin Endocrinol Metab. 1964;24:1076-1082.

7. McIntyre N HC, Turner DS. New interpretation of oral glucose tolerance. Lancet. 1964;2(7349):20-21.

8. Azuma K, Radikova Z, Mancino J, et al. Measurements of islet function and glucose metabolism with the dipeptidyl peptidase 4 inhibitor vildagliptin in patients with type 2 diabetes. J Clin Endocrinol Metab. 2008;93(2):459-464

9. Wani JH J-KJ, Fonseca VA. Dipeptidyl peptidase-4 as a new target of action for type 2 diabetes mellitus: a systematic review. Cardiol Clin. 2008;26(4):639-648.

10. Chia CW CO, Kim W, Shin YK, et al. Exogenous glucose-dependent insulinotropic polypeptide worsens post prandial hyperglycemia in type 2 diabetes. Diabetes. 2009;58(6):1342-1349.

11. Drucker D. Enhancing incretin action for the treatment of type 2 diabetes. Diabetes Care. 2003;26(10):2929-2940.

12. Nauck M SF, Ebert R, Creutzfeldt W. Reduced incretin effect in type 2 (non-insulin-dependent) diabetes. Diabetologia. 1986;29(1):46-52. 
13. Aronoff SL BK, Shreiner B, Want L. Glucose metabolism and regulation: beyond insulin and glucagon. Diabetes Spectrum. 2004; 17(3):183-190.

14. Holst J. Therapy of type 2 diabetes mellitus based on the actions of glucagon-like peptide-1. Diabetes Metab Res Rev. 2002;18(6):430-441.

15. Ahren B, Pacini G, Tura A, Foley JE, Schweizer A. Improved mealrelated insulin processing contributes to the enhancement of B-cell function by the DPP-4 inhibitor vildagliptin in patients with type 2 diabetes. Horm Metab Res. 2007;39(11):826-829.

16. Raz I, Hanefeld M, Xu L, et al. Efficacy and safety of the dipeptidyl peptidase-4 inhibitor sitagliptin as monotherapy in patients with type 2 diabetes mellitus. Diabetologia. 2006;49(11):2564-2571.

17. Mu J WJ, Zhou YP, Roy RS, et al. Chronic inhibition of dipeptidyl peptidase-4 with a sitagliptin analog preserves pancreatic beta-cell mass and function in a rodent model of type 2 diabetes. Diabetes. 2006;55(6):1695-1704.

18. Green BD, Flatt P, Bailey C. Dipeptidyl peptidase IV (DPP IV) inhibitors: a newly emerging drug class for the treatment of type 2 diabetes. Diabetes Vas Dis Res. 2006;3(3):159-165.

19. Lambeir A, Durinx C, Scharpe Ś, De Meester I. Dipeptidyl-peptidase IV from bench to bedside: An update on structural properties, functions, and clinical aspects of the enzyme DPP IV. Critl Rev Clin Lab Sci. 2003;40(3):209-294

20. Aytac U, Dang NH. CD26/Dipeptidyl Peptidase IV: A regulator of immune function and a potential molecular target for therapy. Curr Drug Targets. 2004;4:11-18.

21. Richter B, Bandeira-Echtler E, Bergerhoff K, Lerch C. Dipeptidyl peptidase-4(DPP-4) inhibitors for type 2 diabetes mellitus. Cochrane Database Syst Rev. 2008 Apr 16;(2):CD006739.

22. Lankas GR, Leiting B, Roy RS, et al. Dipeptidyl peptidase IV inhibition for the treatment of type 2 diabetes potential importance of selectivity over dipeptidyl peptidases 8 and 9. Diabetes. 2005;54:2988-2994.

23. Holst JJ, Deacon CF, Inhibition of the activity of dipeptidylpeptidase IV as a treatment for type 2 diabetes. Diabetes. 1998;47: 1663-1670.

24. Kirby M, Yu D, O'Connor S, Gorrell M. Inhibitor selectivity in the clinical application of dipeptidyl peptidase-4 inhibition. Clin Sci. 2010;118:31-41.

25. Bergman AJ, Stevens C, Zhou Y, et al. Pharmacokinetic and pharmacodynamic properties of multiple oral doses of sitagliptin, a dipeptidyl peptidase-IV inhibitor: a double-blind, randomized, placebo-controlled study in healthy male volunteers. Clin Ther. 2006;28(1):55-72.

26. Herman GA, Stevens C, Van Dyck K, et al. Pharmacokinetics and pharmacodynamics of sitagliptin, an inhibitor of dipeptidyl peptidase IV, in healthy subjects: results from two randomized, double-blind, placebo-controlled studies with single oral doses. Clin Pharmacol Ther. 2005 Dec;78(6):675-688.

27. Herman GA, Bergman A, Liu F, et al. Pharmacokinetics and pharmacodynamic effects of the oral DPP-4 inhibitor sitagliptin in middle-aged obese subjects. J Clin Pharmacol. 2006 Aug;46(8):876-886.

28. He H, Tran P, Yin H, et al. Absorption, metabolism, and excretion of [14C]vildagliptin, a novel dipeptidyl peptidase 4 inhibitor, in humans. Drug Metab Dispos. 2009;37(3):536-544.

29. Onglyza (saxagliptin) full prescribing information. [Cited 2009 Oct 26]. Available from: http://packageinserts.bms.com/pi/pi_onglyza.pdf.

30. Chan JC, Scott R, Arjona Ferreira JC, et al. Safety and efficacy of sitagliptin in patients with type 2 diabetes and chronic renal insufficiency. Diabetes Obes Metab. 2008;10(7):545-555.

31. Bergman AJ CJ, Yi B, Marbury T, et al. Effect of renal insufficiency on the pharmacokinetics of sitagliptin, a dipeptidyl peptidase-4 inhibitor. Diabetes Care. 2007;30(7):1862-1864.

32. Rosenstock J, Brazg R, Andryuk PJ, Lu K, Stein P; Sitagliptin Study Group. Efficacy and safety of the dipeptidyl peptidase-4 inhibitor sitagliptin added to ongoing pioglitazone therapy in patients with type 2 diabetes: a 24-week, multicenter, randomized, double-blind, placebo-controlled, parallel-group study. Clin Ther. 2006;28(10): 1556-1568.
33. Herman GA, Bergman A, Yi B, Kipnes M; The Sitagliptin Study Group. Tolerability and pharmacokinetics of metformin and the dipeptidyl peptidase-4 inhibitor sitagliptin when co-administered in patients with type 2 diabetes. Curr Med Res Opin. 2006;22(10):1939-1947.

34. Mistry GC, Bergman AJ, Luo WL, et al. Multiple-dose administration of sitagliptin, a dipeptidyl peptidase- 4 inhibitor, does not alter the single-dose pharmacokinetics of rosiglitazone in healthy subjects. J Clin Pharmacol. 2007;47(2):159-164.

35. Mistry GC, Bergman AJ, Zheng W, et al. Sitagliptin, an dipeptidyl peptidase-4 inhibitor, does not alter the pharmacokinetics of the sulphonylurea, glyburide, in healthy subjects. Br J Clin Pharmacol. Jul 2008;66(1):36-42.

36. Mohan V, Yang W, Son HY, et al. Efficacy and safety of sitagliptin in the treatment of patients with type 2 diabetes in China, India, and Korea. Diabetes Res Clin Pract. 2009;83(1):106-116.

37. Nonaka K, Kakikawa T, Sato A, et al. Efficacy and safety of sitagliptin monotherapy in Japanese patients with type 2 diabetes. Diabetes Res Clin Pract. 2008;79(2):291-298.

38. He YL, Flannery B, Campestrini J, et al. Effect of food on the pharmacokinetics of a vildagliptin/metformin $(50 / 1000 \mathrm{mg})$ fixeddose combination tablet in healthy volunteers. Curr Med Res Opin. 2008;24(6):1703-17039.

39. He YL, Sabo R, Campestrini J, et al. The effect of age, gender, and body mass index on the pharmacokinetics and pharmacodynamics of vildagliptin in healthy volunteers. Br J Clin Pharmacol. 2008; 65(3):338-346.

40. He YL, Sabo R, Picard F, et al. Study of the pharmacokinetic interaction of vildagliptin and metformin in patients with type 2 diabetes. Curr Med Res Opin. 2009;25(5):1265-1272.

41. Serra D, He YL, Bullock J, et al. Evaluation of pharmacokinetic and pharmacodynamic interaction between the dipeptidyl peptidase IV inhibitor vildagliptin, glyburide and pioglitazone in patients with Type 2 diabetes. Int J Clin Pharmacol Ther. 2008;46(7):349-364.

42. He YL, Ligueros-Saylan M, Sunkara G, et al. Vildagliptin, a novel dipeptidyl peptidase IV inhibitor, has no pharmacokinetic interactions with the antihypertensive agents amlodipine, valsartan, and ramipril in healthy subjects. J Clin Pharmacol. 2008;48(1):85-95.

43. Ayalasomayajula SP, Dole K, He YL, et al. Evaluation of the potential for steady-state pharmacokinetic interaction between vildagliptin and simvastatin in healthy subjects. Curr Med Res Opin. 2007; 23(12):2913-2920.

44. He YL, Sabo R, Sunkara G, et al. Evaluation of pharmacokinetic interactions between vildagliptin and digoxin in healthy volunteers. J Clin Pharmacol. 2007;47(8):998-1004.

45. He YL, Sabo R, Riviere GJ, et al. Effect of the novel oral dipeptidyl peptidase IV inhibitor vildagliptin on the pharmacokinetics and pharmacodynamics of warfarin in healthy subjects. Curr Med Res Opin. 2007;23(5):1131-1138

46. Hu P, Yin Q, Deckert F, et al. Pharmacokinetics and pharmacodynamics of vildagliptin in healthy Chinese volunteers. J Clin Pharmacol. 2009;49(1):39-49.

47. Rosenstock J, Aguilar-Salinas C, Klein E, Nepal S, List J, Chen R; for the CV181-011 Study Investigators. Effect of saxagliptin monotherapy in treatment-nave patients with type 2 diabetes. Current Medical Research and Opinion. 2009;25(10):2401-2411.

48. Christopher R, Covington P, Davenport M, et al. Pharmacokinetics, pharmacodynamics, and tolerability of single increasing doses of the dipeptidyl peptidase-4 inhibitor alogliptin in healthy male subjects. Clin Ther. 2008;30(3):513-527.

49. Heise T, Graefe-Mody EU, Hüttner S, Ring A, Trommeshauser D, Dugi KA. Pharmacokinetics, pharmacodynamics and tolerability of multiple oral doses of linagliptin, a dipeptidyl peptidase-4 inhibitor in male type 2 diabetes patients. Diabetes Obes Metab. 2009; 11(8):786-794.

50. Amori R, Lau J, Pittas A. Efficacy and safety of incretin therapy in type 2 diabetes: systematic review and meta-analysis. JAMA. 2007; 298(2):194-206 
51. Monami M, Iacomelli I, Marchionni N, Mannucci E. Dipeptidyl-peptidase-4 inhibitors in type 2 diabetes: a meta-analysis of randomized clinical trials. Nutr Metab Cardiovasc Dis. 2009; DOI:10.1016/j.numecd.2009.03.015.

52. Raz I, Chen Y, Wu M, et al. Efficacy and safety of sitagliptin added to ongoing metformin therapy in patients with type 2 diabetes. Curr Med Res Opin. 2008;24(2):537-550.

53. Charbonnel B, Karasik A, Liu J, Wu M, Meininger G; Sitagliptin Study Group. Efficacy and safety of the dipeptidyl peptidase-4 inhibitor sitagliptin added to ongoing metformin therapy in patients with type 2 diabetes inadequately controlled with metformin alone. Diabetes Care. 2006;29(12):2638-2643.

54. Scott R, Loeys T, Davies MJ, Engel SS; Sitagliptin Study 801 Group. Efficacy and safety of sitagliptin when added to ongoing metformin therapy in patients with type 2 diabetes. Diabetes Obes Metab. 2008;10(10):959-969.

55. Hermansen K, Kipnes M, Luo E, et al. Efficacy and safety of the dipeptidyl peptidase- 4 inhibitor, sitagliptin, in patients with type 2 diabetes mellitus inadequately controlled on glimepiride alone or on glimepiride and metformin. Diabetes Obes Metab. 2007;9(5):733- L745.

56. Goldstein BJ, Feinglos MN, Lunceford JK, Johnson J, WilliamsHerman DE, Sitagliptin 036 Study Group. Effect of initial combination therapy with sitagliptin, a dipeptidyl peptidase-4 inhibitor, and metformin on glycemic control in patients with type 2 diabetes. Diabetes Care. 2007;30(8):1979-1987.

57. Nauck MA, Meininger G, Sheng D, Terranella L, Stein PP; Sitagliptin Study Group. Efficacy and safety of the dipeptidyl peptidase-4 inhibitor, sitagliptin, compared with the sulfonylurea, glipizide, in patients with type 2 diabetes inadequately controlled on metformin alone: a randomized, double-blind, non-inferiority trial. Diabetes Obes Metab. 2007;9(2):194-205.

58. DeFronzo RA, Okerson T, Viswanathan P, Guan X, Holcombe JH, MacConell L. Effects of exenatide versus sitagliptin on postprandial glucose, insulin and glucagon secretion, gastric emptying, and caloric intake: a randomized, cross-over study. Curr Med Res Opin. 2008;24(10):2943-2952.

59. Bosi E, Camisasca RP, Collober C, Rochotte E, Garber AJ. Effects of vildagliptin on glucose control over 24 weeks in patients with type 2 diabetes inadequately controlled with metformin. Diabetes Care. 2007;30(4):890-895.

60. Ahrén B, Pacini G, Foley JE, Schweizer A. Improved meal-related beta-cell function and insulin sensitivity by the dipeptidyl peptidase-IV inhibitor vildagliptin in metformin-treated patients with type 2 diabetes over 1 year. Diabetes Care. 2005;28(8):1936-1940.

61. Garber AJ, Foley JE, Banerji MA, et al. Effects of vildagliptin on glucose control in patients with type 2 diabetes inadequately controlled with a sulphonylurea. Diabetes Obes Metab. 2008;10(11):1047-1056.

62. Garber AJ, Schweizer A, Baron MA, Rochotte E, Dejager S. Vildagliptin in combination with pioglitazone improves glycaemic control in patients with type 2 diabetes failing thiazolidinedione monotherapy: a randomized, placebo-controlled study. Diabetes Obes Metab. 2007;9(2):166-174.

63. Fonseca V, Schweizer A, Albrecht D, Baron MA, Chang I, Dejager S. Addition of vildagliptin to insulin improves glycaemic control in type 2 diabetes. Diabetologia. 2007;50(6):1148-1155.

64. Rosenstock J, Baron MA, Dejager S, Mills D, Schweizer A. Comparison of vildagliptin and rosiglitazone monotherapy in patients with type 2 diabetes: a 24-week, double-blind, randomized trial. Diabetes Care. 2007;30(2):217-223.

65. Rosenstock J, Kim SW, Baron MA, et al. Efficacy and tolerability of initial combination therapy with vildagliptin and pioglitazone compared with component monotherapy in patients with type 2 diabetes. Diabetes Obes Metab. 2007;9:175-185.

66. Bolli G, Dotta F, Rochotte E, Cohen SE. Efficacy and tolerability of vildagliptin vs. pioglitazone when added to metformin: a 24-week, randomized, double-blind study. Diabetes Obes Metab. 2008;10(1): $82-90$.
67. Pan C, Yang W, Barona JP, et al. Comparison of vildagliptin and acarbose monotherapy in patients with Type 2 diabetes: a 24-week, double-blind, randomized trial. Diabet Med. 2008;25(4):435-441.

68. Schweizer A, Couturier A, Foley JE, Dejager S. Comparison between vildagliptin and metformin to sustain reductions in $\mathrm{HbA}(1 \mathrm{c})$ over 1 year in drug-naive patients with Type 2 diabetes. Diabet Med. 2007;24(9):955-961.

69. Goke B, Hershon K, Kerr D, et al. Efficacy and safety of vildagliptin monotherapy during 2-year treatment of drug-naive patients with type 2 diabetes: comparison with metformin. Horm Metab Res. 2008;40(12):892-895.

70. Aschner P, Kipnes MS, Lunceford JK, et al. Effect of the dipeptidyl peptidase-4 inhibitor sitagliptin as monotherapy on glycemic control in patients with type 2 diabetes. Diabetes Care. 2006;29(12):2632-2637.

71. Pratley RE, Jauffret-Kamel S, Galbreath E, Holmes D. Twelve-week monotherapy with the DPP-4 inhibitor vildagliptin improves glycemic control in subjects with type 2 diabetes. Horm Metab Res. 2006;38(6):423-428

72. Rosenstock J, Sankoh S, List JF. Glucose-lowering activity of the dipeptidyl-peptidase-4 inhibitor saxagliptin in drug-naive patients with type 2 diabetes. Diab Obes Metab. 2008;10:376-386.

73. DeFronzo R, Hissa M, Garber A, et al. For the saxagliptin 014 study group. The efficacy and safety of saxagliptin when added to metformin therapy in patients with inadequately controlled type 2 diabetes with metformin alone. Diabetes Care. 2009;32(9):1649-1655.

74. Chacra AR, Tan GH, Apanovitch A, Ravichandran S, List J, Chen R; for the CV181-040 Investigators. Saxagliptin added to a submaximal dose of sulphonylurea improves glycaemic control compared with uptitration of sulphonylurea in patients with type 2 diabetes: a randomized controlled trial. Int J Clin Pract. 2009;63(9):1395-1406.

75. Jadzinksy M, Pfutzner A, Paz-Pacheco E, Xu Z, Allen E, Chen R; for the CV181-038 Investigators. Saxagliptin given in combination with metformin as initial therapy improves glycaemic control in patients with type 2 diabetes compared with either monotherapy: a randomized controlled trial. Diab Obes Metab. 2009;11:611-622.

76. Nauck MA, Ellis GC, Fleck PR, Wilson CA, Mekki Q; for the Alogliptin Study 008 Group. Efficacy and safety of adding the dipeptidyl-peptidase-4 inhibitor alogliptin to metformin therapy in patients with type 2 diabetes inadequately controlled with metformin monotherapy: a multicentre, randomised, double-blind, placebo-controlled study. Int J Clin Pract. 2009;63:46-55.

77. Pratley RE, Kipnes MS, Fleck PR, Wilson C, Mekki Q; on behalf of the Alogliptin Study 007 Group. Efficacy and safety of the dipeptidyl-peptidase-4 inhibitor alogliptin in patients with type 2 diabetes inadequately controlled by glyburide monotherapy. Diab Obes Metab. 2009;11:167-176.

78. Rosenstock J, Rendell MS, Gross JL, Fleck PR, Wilson CA, Mekki Q. Alogliptin added to insulin therapy in patients with type 2 diabetes reduces $\mathrm{HbA}_{1 \mathrm{c}}$ without causing weight gain or increased hypoglycaemia. Diab Obes Metab. 2009. DOI:10.1111/j.1463-1326.2009.01124.x.

79. Clinicaltrials.gov. Gov\#NCT00915772. [Cited 2009 Oct 10].

80. Clinicaltrials.gov. Gov\#NCT00954447. [Cited 2009 Oct 10].

81. Hanefeld M, Herman GA, Wu M, Mickel C, Sanchez M, Stein PP; Sitagliptin Study 014 Investigators. Once-daily sitagliptin, a dipeptidyl peptidase- 4 inhibitor, for the treatment of patients with type 2 diabetes. Curr Med Res Opin. 2007;23(6):1329-1339.

82. Scott R, Wu M, Sanchez M, Stein P. Efficacy and tolerability of the dipeptidyl peptidase-4 inhibitor sitagliptin as monotherapy over 12 weeks in patients with type 2 diabetes. Int J Clin Pract. 2007;61(1):171-180.

83. Scherbaum WA, Schweizer A, Mari A, et al. Evidence that vildagliptin attenuates deterioration of glycaemic control during 2-year treatment of patients with type 2 diabetes and mild hyperglycaemia. Diabetes Obes Metab. 2008;10(11):1114-1124.

84. Ristic S, Byiers S, Foley J, Holmes D. Improved glycaemic control with dipeptidyl peptidase-4 inhibition in patients with type 2 diabetes: vildagliptin (LAF237) dose response. Diabetes Obes Metab. 2005;7(6): 692-698. 
85. Mari A, Scherbaum WA, Nilsson PM, et al. Characterization of the influence of vildagliptin on model-assessed cell function in patients with type 2 diabetes and mild hyperglycaemia. Diabetes Obes Metab. 2008;10:675-682.

86. Rosenstock J, Foley JE, Rendell M, et al. Effects of the dipeptidyl peptidase-IV inhibitor vildagliptin on incretin hormones, islet function, and postprandial glycemia in subjects with impaired glucose tolerance. Diabetes Care. 2008 Jan;31(1):30-35.

87. D'Alessio DA, Denney AM, Hermiller LM, et al. Treatment with the dipeptidyl peptidase-4 inhibitor vildagliptin improves fasting islet-cell function in subjects with type 2 diabetes. J Clin Endocrinol Metab. 2009;94(1):81-88.

88. Baggio LL, Drucker DJ. Therapeutic approaches to preserve islet mass in type 2 diabetes. Annu Rev Med. 2006;57:265-281.

89. Moritoh Y, Takeuchi K, Asakawa T, Kataoka O,Odaka H. Combining a dipeptidyl peptidase-4 inhibitor, alogliptin, with pioglitazone improves glycaemic control, lipid profiles and $\beta$-cell function in $\mathrm{db} / \mathrm{db}$ mice. Brit J of Pharm. 2009;157(3):415-426.

90. Meece J. Pancreatic islet dysfunction in type 2 diabetes: a rational target for incretin-based therapies. Curr Med Res Opin. 2007; 23(4):933-944.

91. Herman GA, Bergman A, Stevens C, et al. Effect of single oral doses of sitagliptin, a dipeptidyl peptidase-4 inhibitor, on incretin and plasma glucose levels following an oral glucose tolerance test in patients with type 2 diabetes. J Clin Endocrinol Metab. 2006;91:4612-4619.

92. Vella A, Bock G, Giesler PD, et al. Effects of dipeptidyl peptidase-4 inhibition on gastrointestinal function, meal appearance, and glucose metabolism in type 2 diabetes. Diabetes. 2007;56(5): 1475-1480.

93. Russell-Jones D. Molecular, pharmacological, and clinical aspects of liraglutide, a once-daily human GLP-1 analogue. Mol Cell Endocrinol. 2009;297(1-2):137-140.

94. Buse J, Klonoff D, Nielsen L, et al. Metabolic effects of two years of exenatide treatment on diabetes, obesity, and hepatic biomarkers in patients with type 2 diabetes: An interim analysis of data from the open-label, uncontrolled extension of three double-blind, placebocontrolled trial. Clin Ther. 2007;29(1):139-153.

95. Matikainen N, Mänttäri S, Schweizer A, et al. Vildagliptin therapy reduces postprandial intestinal triglyceride-rich lipoprotein particles in patients with type 2 diabetes. Diabetologia. 2006;49(9):2049-2057.

96. MERCK. Januvia (sitagliptin) tablets. Available from: http://www. januvia.com/sitagliptin/januvia/consumer/index.jsp. [Cited 2009 October 8].
97. Novartis Pharmaceuticals UK Ltd. Galvus $50 \mathrm{mg}$ tablets [online] [Updated 2009 Sept; cited 2009 Oct 26]. Available from: http://www.emc. medicines.org.uk/medicine/20734/SPC/Galvus+50+mg+Tablets/.

98. Deacon C. MK-431 (Merck). Current Opinion in Investigational Drugs. 2005;6:419-426.

99. FDA post-marketing drug safety information. Available from: http:// www.fda.gov/Drugs/DrugSafety/PostmarketDrugSafetyInformationforPatientsandProviders/DrugSafetyInformationforHeathcareProfessionals/ucm183764.htm. [Cited 2009 Sept 19].

100. Ahmad SR SJ. Exenatide and rare adverse events. $N$ Engl J Med. 2008;358(18):1970-1971.

101. Koehler J, Baggio L, Lamont B, Ali S, Drucker D. Glucagon-like peptide-1 receptor activation modulates pancreatitis-associated gene expression but does not modify the susceptibility to experimental pancreatitis in mice. Diabetes. 2009;58:2148-2161.

102. Matveyenko AV, Dry S, Cox HI, et al. Beneficial endocrine but adverse exocrine effects of sitagliptin in the human islet amyloid polypeptide transgenic rat model of type 2 diabetes: interactions with metformin. Diabetes. 2009;58(7):1604-1615.

103. Dore DD, Seeger JD, Arnold Chan K. Use of a claims-based active drug safety surveillance system to assess the risk of acute pancreatitis with exenatide or sitagliptin compared to metformin or glyburide. Curr Med Res Opin. 2009;25(4):1019-1027.

104. US Department of Health and Human Services, Food and Drug Administration, Center for Drug Evaluation and Research. Guidance for Industry: Diabetes mellitus-evaluating cardiovascular risk in new antidiabetic therapies to treat type 2 diabetes. http://www.fda.gov/cder/ guidance/index.htm. [Updated 2008 Dec; cited 2009 Oct 10].

105. Dhillon S, Weber J. Saxagliptin. Drugs. 2009;69(15):2103-2114.

106. TECOS-Study.org [homepage on the Internet]. University of Oxford; Trial Evaluating Cardiovascular Outcomes with Sitagliptin. [cited 2009 Oct 26.] Available from: http://www.tecos-study.org

107. Pi-Sunjer FX, Schweizer A, Mills D, Dejager S. Efficacy and tolerability of vildagliptin monotherapy in drug-naïve patients with type 2 diabetes. Diabetes Res Clin Pract. 2007;76(1):132-138.

108. Dejager S, Razac S, Foley JE, Schweizer A. Vildagliptin in drug-naïve patients with type 2 diabetes: a 24-week, double-blind, randomized, placebo-controlled, multiple-dose study. Horm Metab Res. 2007;39(3):218-223.

109. Scherbaum WA, Schweizer A, Mari A, et al. Efficacy and tolerability of vildagliptin in drug-naïve patients with type 2 diabetes and mild hyperglycemia. Diabetes Obes Metab. 2008;10(8):675-682.
Drug, Healthcare and Patient Safety

\section{Publish your work in this journal}

Drug, Healthcare and Patient Safety is an international, peer-reviewed open-access journal exploring patient safety issues in the healthcare continuum from diagnostic and screening interventions through to treatment, drug therapy and surgery. The journal is characterized by the rapid reporting of reviews, original research, clinical, epidemiological and

\section{Dovepress}

post-marketing surveillance studies, risk management, health literacy and educational programs across all areas of healthcare delivery. The manuscript management system is completely online and includes a very quick and fair peer-review system. Visit http://www.dovepress.com/ testimonials.php to read real quotes from published authors. 